\title{
T-Gate shaped AIN/B-Ga2O3 HEMT for RF and High Power Nanoelectronics
}

This paper was downloaded from TechRxiv (https://www.techrxiv.org).

\section{LICENSE}

CC BY 4.0

SUBMISSION DATE / POSTED DATE

20-07-2021 / 02-08-2021

\section{CITATION}

Singh, Rajan; Lenka, Trupti; Nguyen, Hieu (2021): T-Gate shaped AIN/ß-Ga2O3 HEMT for RF and High Power Nanoelectronics. TechRxiv. Preprint. https://doi.org/10.36227/techrxiv.15023094.v1

$\mathrm{DOI}$

10.36227/techrxiv.15023094.v1 


\section{T-Gate shaped AlN $/ \beta-\mathrm{Ga}_{2} \mathrm{O}_{3} \mathrm{HEMT}$ for RF and High Power Nanoelectronics}

\author{
Rajan Singh \\ Department of Electronics and \\ Communication Engineering, \\ National Institute of Technology \\ Silchar, \\ Assam, India \\ Email: rajan_rs@ece.nits.ac.in
}

\author{
T. R. Lenka \\ Department of Electronics and \\ Communication Engineering, \\ National Institute of Technology \\ Silchar, \\ Assam, India \\ Email: trlenka@ieee.org
}

\author{
H. P. T. Nguyen \\ Department of Electrical and Computer \\ Engineering, \\ New Jersey Institute of Technology \\ Newark, \\ New Jersey, USA \\ Email: hieu.p.nguyen@njit.edu
}

\begin{abstract}
In this paper, we report record DC and RF performance in $\beta-\mathrm{Ga}_{2} \mathrm{O}_{3}$ High Electron Mobility Transistor (HEMT) with field-plate T-gate using 2-D simulations. The T gate with head-length $L_{H L}$ of $180 \mathrm{~nm}$ and foot-length $L_{F L}$ of 120 $\mathrm{nm}$ is used in the highly scaled device with an aspect ratio $\left(\mathrm{L}_{\mathrm{G}} / \mathrm{t}_{\text {barrier }}\right)$ of $\sim 5$. The proposed device takes advantage of a highly polarized Aluminum Nitride (AIN) barrier layer to achieve high Two-Dimensional Electron Gas (2DEG) density in the order of $2.3 \times 10^{13} \mathrm{~cm}^{-2}$, due to spontaneous as well as piezoelectric polarization components. In the depletion mode operation, maximum drain current $I_{D, M A X}$ of $1.32 \mathrm{~A} / \mathrm{mm}$, and relatively flat transconductance characteristics with a maximum value of $0.32 \mathrm{~S} / \mathrm{mm}$ are measured. The device with source-drain distance $L_{S D}$ of $1.9 \mu \mathrm{m}$ exhibits record low specificon resistance $R_{O N, s p}$ of $0.136 \mathrm{~m} \Omega-\mathrm{cm}^{-2}$, and off-state breakdown voltage of $403 \mathrm{~V}$, which correspond to the record power figureof-merit (PFoM) of $\sim 1194 \mathrm{MW} / \mathrm{cm}^{2}$. Additionally, current gain cut-off frequency $f_{T}$ and maximum oscillation frequency $f_{\text {MAX }}$ of 48 and $142 \mathrm{GHz}$ are estimated. The obtained results show the potential of $\mathrm{Ga}_{2} \mathrm{O}_{3}$ HEMT for futuristic power devices.
\end{abstract}

Keywords-Beta-Gallium oxide ( $\left(\beta-\mathrm{Ga}_{2} \mathrm{O}_{3}\right)$, High-ElectronMobility-Transistor (HEMT), Power Figure-of-Merit (PFoM), TGate, Polarization, On-resistance (Ron), Breakdown voltage $\left(V_{B R}\right)$.

\section{INTRODUCTION}

Despite challenges on the front of high-quality native substrates, GaN-based HEMTs have been in use for over a decade and probably surpassed their life-cycle, for various reasons [1]. Currently, gallium-oxide $\left(\mathrm{Ga}_{2} \mathrm{O}_{3}\right)$ is being thoroughly explored for its possible applications in certain areas of power electronics due to its interesting material properties such as large bandgap $(4.5-5.3 \mathrm{eV})$, estimated high critical field $(8 \mathrm{MV} / \mathrm{cm})$, a wide variety of n-type dopants with controllable doping, and availability of single-crystal substrate grown using melt-based systems [2]-[4]. Out of its five crystalline structures, the $\beta$-phase of $\mathrm{Ga}_{2} \mathrm{O}_{3}$ has been reported as the most stable and looks most suited to high-voltage applications. The constant growth and development of $\beta$ $\mathrm{Ga}_{2} \mathrm{O}_{3}$ single crystal technology are further fuelling the search for a suitable wide-bandgap (WBG) material, having the potential to supplement existing technologies as well as capable to address new emerging power applications.

The $\beta-\mathrm{Ga}_{2} \mathrm{O}_{3}$ device technology has a footprint in almost all power devices including Schottky barrier diodes [5], [6], MESFETs [7], [8], MOSFETs: depletion-mode (D-mode) [9]-[12] and enhancement-mode (E-mode) [13]-[17], and HEMTs [18], [19]. Specifically, a high breakdown field of 3.8 and 5.2 MV/cm is reported in $\beta-\mathrm{Ga}_{2} \mathrm{O}_{3}$ lateral MOSFET [10] and $\beta-\mathrm{Ga}_{2} \mathrm{O}_{3}$ vertical heterostructure [20]. In addition, a power Figure of Merit (PFoM) $V_{B R}^{2} / R_{O N, s p}$ of 11 and $192.5 \mathrm{MW} / \mathrm{cm}^{2}$ are reported in [10], and [17] respectively. However, these devices have used relatively thick epi-channel of $200 \mathrm{~nm}$ and large gate length of $>1 \mu \mathrm{m}$ together make them less relevant for RF applications. The high frequency applications demand aggressive device scaling, both lateral as well as vertical. On the other hand sub-micron gate led to poor control as well as deteriorated transconductance and current gain due to increased gate-resistance [21]. The T-gate technology enables use of short gate-length while keeping the gate-resistance low simultaneously [21]. It is worth to note that, the switching performance of a power switch critically depends on OFFstate leakage and $\mathrm{ON}$-state conduction loss due to finite $\mathrm{ON}$ resistance. Furthermore, the ON-resistance $\left(\mathrm{R}_{\mathrm{ON}}\right)$ of the device is proportional to gate-drain length $\left(\mathrm{L}_{\mathrm{GD}}\right)$ and sheet-resistance $\left(\mathrm{R}_{\mathrm{SH}}\right)$ of the 2DEG channel.

In this paper, 2-D simulations of $\mathrm{AlN} / \beta-\mathrm{Ga}_{2} \mathrm{O}_{3} \mathrm{HEMT}$ are performed to access its switching performance using a physics-based device simulator. The DC and RF characteristics of the proposed device are thoroughly investigated. The following section describes the proposed device architecture and simulation settings, followed by results and discussion in Section III. Results are also benchmarked against similar device structure presented recently. Section IV concludes the paper.

\section{DEVICE Structure AND Simulation Framework}

The proposed device schematic cross-section is shown in Fig. 1. The epitaxial layer sequence is arranged as follows. On a semi-insulating $\beta$ - $\mathrm{Ga}_{2} \mathrm{O}_{3}$ substrate, $0.275 \mu \mathrm{m} \beta$ - $\mathrm{Ga}_{2} \mathrm{O}_{3}$ buffer layer exists, which is doped with acceptor-like traps to account for unintentional Fe-dopants, followed by a $10 \mathrm{~nm}$ thick AlN material as a barrier layer on which Schottky gate contact with a barrier height of $0.8 \mathrm{eV}$ is fixed. The source/drain contacts are assumed to be ohmic, and contact resistance of $0.4 \Omega-\mathrm{mm}$ is assumed as measured in [22]. The low contact resistance is achieved using a heavily doped n-type Gaussian profile with a peak concentration of $6 \times 10^{19} \mathrm{~cm}^{-3}$. The $\beta-\mathrm{Ga}_{2} \mathrm{O}_{3}$ material parameters and user-defined model parameters are mentioned at places where used, whereas the default physical models are used as given in [23]. The gate length, $\mathrm{L}_{\mathrm{G}}$ equal to T-gate foot length $\left(\mathrm{L}_{\mathrm{FL}}\right)$ of $120 \mathrm{~nm}$ and T-gate head length $\left(\mathrm{L}_{\mathrm{HL}}\right)$ of 180 $\mathrm{nm}$. The gate-source $\left(\mathrm{L}_{\mathrm{GS}}\right)$ and gate-drain distance $\left(\mathrm{L}_{\mathrm{GD}}\right)$ are equal to 0.32 and $1.4 \mu \mathrm{m}$ respectively. Spontaneous and piezoelectric polarization models are evoked for the AlN barrier layer with default settings given in [23]. Apart from 


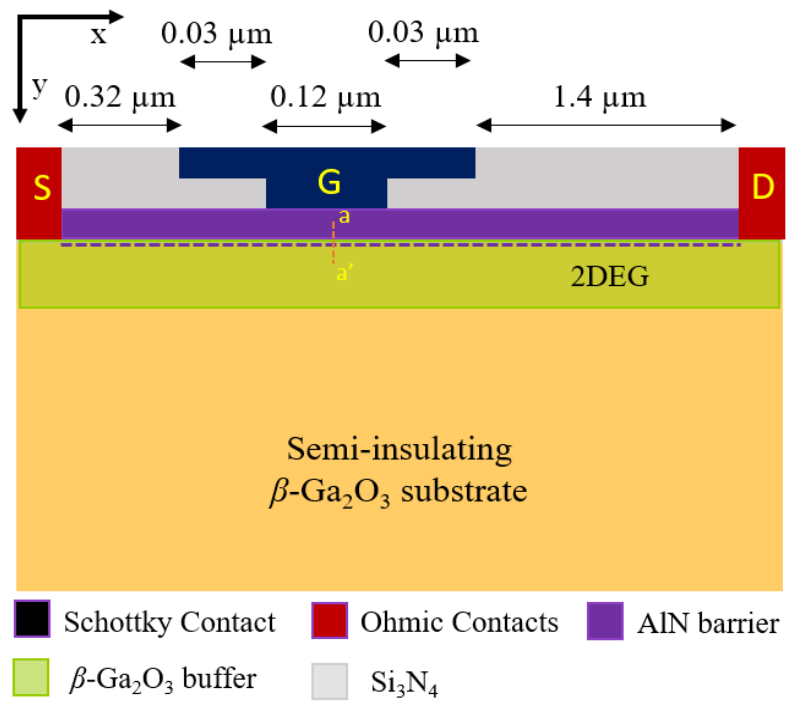

Fig. 1. Schematic of the investigated T-gate $\mathrm{AlN} / \beta-\mathrm{Ga}_{2} \mathrm{O}_{3}$ HEMT, ohmic contacts access regions are $\mathrm{n}^{+}$doped (not shown here).

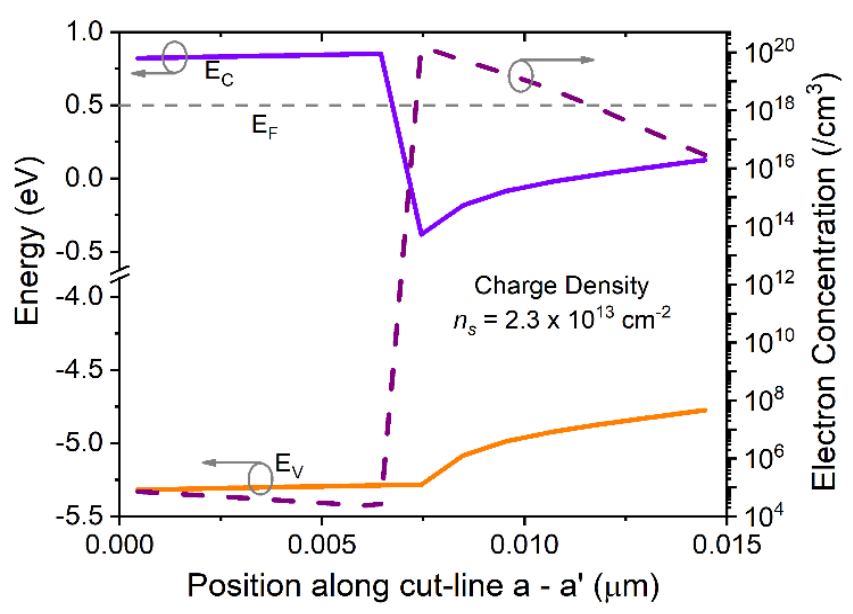

Fig. 2. Energy band diagram and electron concentration along the cut-line a - a' (shown in Fig. 1).

Shockley-Read-Hall (SRH) recombination, Fermi-Dirac for carrier statistics, electric field dependent mobility modelnegative differential conductivity (NDC) is used to capture electron velocity saturation effect. To analyze breakdown characteristics, the impact ionization model-Selberherr is used.

The band bending and electron concentration at the heterointerface along the cut-line $\mathrm{a}-\mathrm{a}$ ' are shown in Fig. 2. The 2DEG density is estimated to be $2.3 \times 10^{13} \mathrm{~cm}^{-2}$. This high 2DEG density is attributed to high polarization charges confined in large conduction band offset $\left(\Delta \mathrm{E}_{\mathrm{C}}\right)$. The $\beta-\mathrm{Ga}_{2} \mathrm{O}_{3}$ material parameters such as energy bandgap $\mathrm{E}_{\mathrm{G}}$ of $4.9 \mathrm{eV}$, static dielectric constant $\left(\varepsilon_{\mathrm{s}}\right)$ of 10.2 are taken from [24]. Using electron effective mass for conduction and valence band, total densities $\mathrm{N}_{\mathrm{C}}$ and $\mathrm{N}_{\mathrm{V}}$ of $3.6 \times 10^{18}$ and $2.86 \times 10^{20}$ $\mathrm{cm}^{-3}$ respectively, are used in the simulation deck. The $\beta$ $\mathrm{Ga}_{2} \mathrm{O}_{3}$ substrate is doped with acceptor as well as the donorlike trap of density $1 \times 10^{18} \mathrm{~cm}^{-3}$ and at energy level $0.82,4.4$ $\mathrm{eV}$ respectively. Different $\beta-\mathrm{Ga}_{2} \mathrm{O}_{3}$ impact ionization coefficients for the Selberherr model [23] are taken from [25]. Electric field dependent mobility model NDC [26] is given as follows:

$$
\mu_{n}(E)=\frac{\mu_{0}+\frac{v_{s a t}}{E}\left(\frac{E}{E_{C}}\right)^{\gamma}}{1+\left(\frac{E}{E_{C}}\right)^{\gamma}}
$$

where $v_{\text {sat }}=1.5 \times 10^{7} \mathrm{~cm} / \mathrm{s}$ is the saturation velocity, $E_{C}=$ $200 \mathrm{kV} / \mathrm{cm}$ is the breakdown electric field, $\mu_{0}=140 \mathrm{~cm}^{2} / \mathrm{V} \mathrm{s}$ is the low-field electron mobility, and $\gamma=2.47$ is the constant.

\section{RESULTS AND DISCUSSION}

This section summarizes the numerical calculation of 2DEG density using polarization models, and simulation results of the T-gate $\mathrm{AlN} / \beta-\mathrm{Ga}_{2} \mathrm{O}_{3} \mathrm{HEMT}$.

\section{A. 2DEG DENSITY}

It is widely reported that a higher value of charge density $\left(\mathrm{n}_{\mathrm{s}}\right)$ is critical for HEMTs operations since the current density is $\propto \mathrm{n}_{\mathrm{s}}$. Since $\beta$ - $\mathrm{Ga}_{2} \mathrm{O}_{3}$ does not possess any polarization property, here only AlN barrier layer polarization is considered to calculate total sheet charge density. Total polarization $\mathrm{P}_{\mathrm{T}}=\mathrm{P}_{\mathrm{SP}}+\mathrm{P}_{\mathrm{PI}}$, where $\mathrm{P}_{\mathrm{SP}}=-0.09 \mathrm{C} / \mathrm{m}^{2}$ [23] is the spontaneous polarization of the AlN material. Due to tensile strain between AlN epitaxial layer and $\beta-\mathrm{Ga}_{2} \mathrm{O}_{3}$ buffer, piezoelectric polarization $\mathrm{P}_{\mathrm{PI}}$ is given as:

$$
P_{P I}=2\left(\frac{a_{s}-a_{0}}{a_{0}}\right) e_{31}-\frac{c_{13}}{c_{33}} e_{33}
$$

where $\mathrm{a}_{\mathrm{s}}=3.112, \mathrm{a}_{0}=3.04$ are the lattice constants of the AlN and $\beta-\mathrm{Ga}_{2} \mathrm{O}_{3}$ materials respectively, and piezoelectric constants are $\mathrm{e}_{31}=-0.53, \mathrm{e}_{33}=-1.5 \mathrm{C} / \mathrm{m}^{2}$, and elastic constants are $\mathrm{C}_{13}=127, \mathrm{C}_{33}=382$ for AlN are used from [23]. So the total polarization $\mathrm{P}_{\mathrm{T}}=-0.612 \mathrm{C} / \mathrm{m}^{2}$, which corresponds to sheet charge density $\mathrm{n}_{\mathrm{s}} \approx 3.8 \times 10^{14} \mathrm{~cm}^{-2}$. However, this value is roughly one order greater than what is estimated through simulation. This can be attributed to the thickness-dependent piezoelectric polarization of the AlN barrier.

\section{B. DC CHARACTERISTICS}

DC electrical transfer characteristics of the proposed device structure are shown in Fig. 3. The maximum value of drain current $\left(\mathrm{I}_{\mathrm{D}, \mathrm{MAX}}\right)$, and transconductance $\left(\mathrm{g}_{\mathrm{M}, \mathrm{MAX}}\right)$ are found to be $1.32 \mathrm{~A} / \mathrm{mm}, 0.32 \mathrm{~S} / \mathrm{mm}$ respectively at $\mathrm{V}_{\mathrm{GS}}=1 \mathrm{~V}$ and $\mathrm{V}_{\mathrm{DS}}=12 \mathrm{~V}$. A relatively 'flat' transconductance is obtained here and better device linearity can be expected. The improved $g_{m}$ linearity is mainly due to the 'coupled' channel of the AlN barrier devices [27]. A threshold voltage $\left(V_{\mathrm{TH}}\right)$ of $-3.8 \mathrm{~V}$ at $\mathrm{I}_{\mathrm{D}}=\mathrm{I}_{\mathrm{D}, \mathrm{MAX}} / 10^{3}$, and $\mathrm{I}_{\mathrm{ON}} / \mathrm{I}_{\mathrm{OFF}}$ greater than $10^{7}$ are extracted from the $\log \mathrm{I}_{\mathrm{D}}-\mathrm{V}_{\mathrm{GS}}$ curve, shown in Fig. 4. Output characteristics of the device, shown in Fig 5, are obtained at the different values of the $\mathrm{V}_{\mathrm{GS}}$ varying from -4 to $1 \mathrm{~V}$ in the step of $1 \mathrm{~V}$. On-resistance $\left(\mathrm{R}_{\mathrm{ON}}\right)$ is calculated corresponding to the linear part of the $\mathrm{I}_{\mathrm{DS}}$. The saturated drain current value of $1.35 \mathrm{~A} / \mathrm{mm}$ is measured at $\mathrm{V}_{\mathrm{DS}}=12 \mathrm{~V}$ and $\mathrm{V}_{\mathrm{GS}}=1 \mathrm{~V}$, which is almost equal to $I_{D, M A X}$.

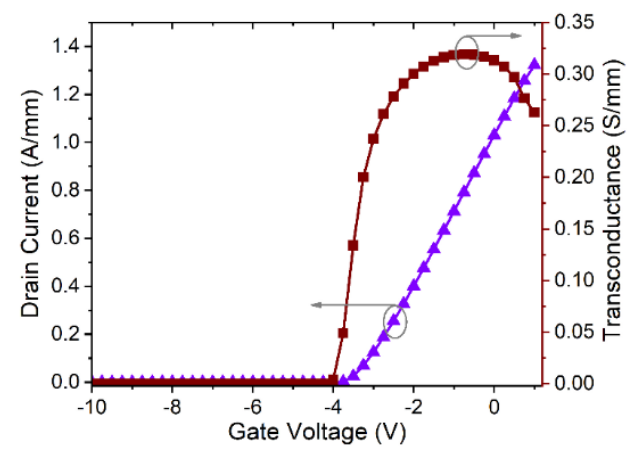

Fig. 3. Transfer characteristics (on a linear scale) of the AlN $/ \beta-\mathrm{Ga}_{2} \mathrm{O}_{3} \mathrm{HEMT}$ showing its transistor operation, $\mathrm{V}_{\mathrm{DS}}=12 \mathrm{~V}$ is used. 


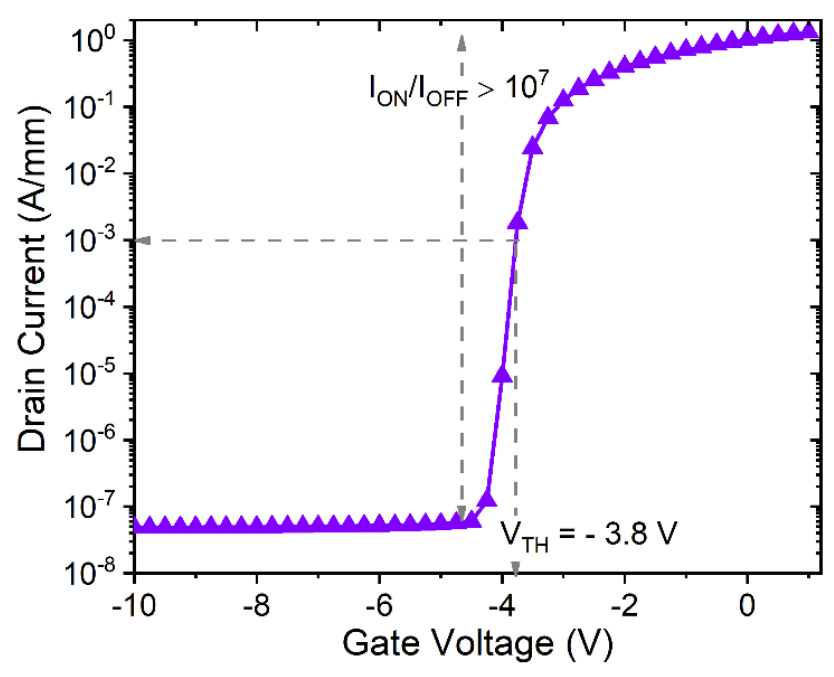

Fig. 4. Fig. 3. Transfer characteristics on $\log$ scale at $\mathrm{V}_{\mathrm{DS}}=12 \mathrm{~V}$, showing $\mathrm{I}_{\mathrm{ON}} / \mathrm{I}_{\mathrm{OFF}}>10^{7}$ and $\mathrm{V}_{\mathrm{TH}}=-3.8 \mathrm{~V}$ measured at $\mathrm{V}_{\mathrm{GS}}$ where $\mathrm{I}_{\mathrm{D}}$ is three orders lower than $\mathrm{I}_{\mathrm{D}, \mathrm{MAX}}$.

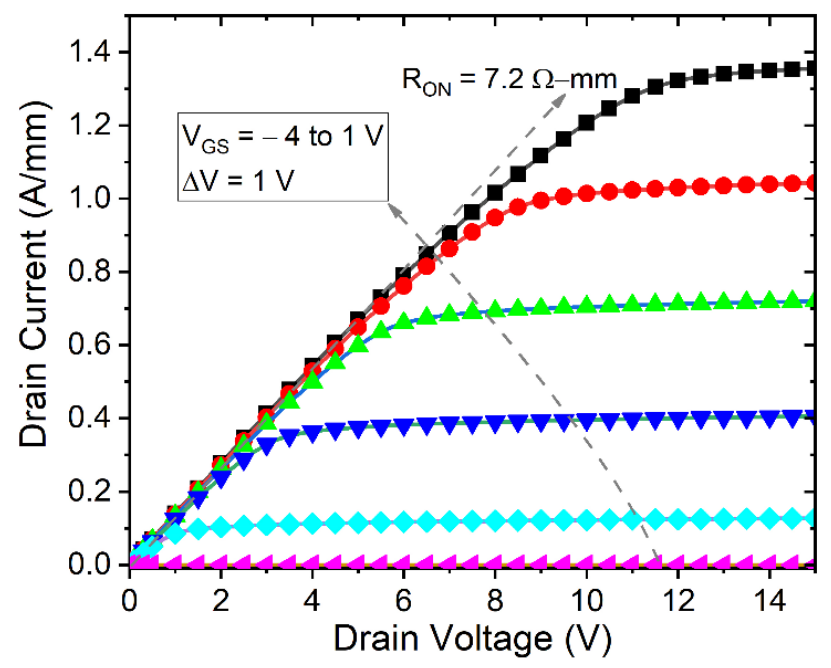

Fig. 5. Output characteristics of the AIN $/ \beta-\mathrm{Ga}_{2} \mathrm{O}_{3} \mathrm{HEMT}$ with $\mathrm{L}_{\mathrm{G}}=0.12$ and $\mathrm{L}_{\mathrm{SD}}=1.9 \mu \mathrm{m}, \mathrm{R}_{\mathrm{ON}}$ corresponding to linear part of $\mathrm{I}_{\mathrm{DS}}$ is indicated.

On-resistance $\left(\mathrm{R}_{\mathrm{ON}}\right)$ of $7.2 \Omega$-mm is extracted using the minimum of $\left(\mathrm{V}_{\mathrm{DS}} / \mathrm{I}_{\mathrm{DS}}\right)$ at $\mathrm{V}_{\mathrm{GS}}=1 \mathrm{~V}$ in the simulation deck. The specific on-resistance $\left(\mathrm{R}_{\mathrm{ON}, \mathrm{sp}}\right)$ of the device is calculated as $\mathrm{R}_{\mathrm{ON}} \times \mathrm{L}_{\mathrm{SD}}=0.136 \mathrm{~m} \Omega-\mathrm{cm}^{2}$. The off-state breakdown voltage of the device is analysed using the Selberherr impact ionization model [23]. The default parameters of the model are replaced by $\beta-\mathrm{Ga}_{2} \mathrm{O}_{3}$ ionization coefficients (an1, an $2=$ $2.16 \times 10^{6}$, bn $1=$ bn $2=1.77 \times 10^{7}$ ) reported in [25]. A minimum current density of $1 \times 10^{-13} \mathrm{~A}$ is used in the simulation deck to trigger the breakdown. Since minority carriers are negligible in a wideband semiconductor like $\beta$ $\mathrm{Ga}_{2} \mathrm{O}_{3}$, numerical method-CLIMIT employed only one carrier-electrons. Compliance parameter is used to set current boundary conditions set at $1 \mathrm{~mA} / \mathrm{mm}$. The off-state breakdown voltage $\left(\mathrm{V}_{\mathrm{BR}}\right)$ of the proposed structure with fieldplate $\mathrm{T}$-gate is estimated to be $403 \mathrm{~V}$ at $\mathrm{V}_{\mathrm{GS}}=-5 \mathrm{~V}$. The threeterminal breakdown characteristics are shown in Fig. 6. The peak electric field distribution at the breakdown is shown in Fig. 7. Moreover, the $\mathrm{AlN} / \beta-\mathrm{Ga}_{2} \mathrm{O}_{3} \mathrm{HEMT}$ with $\mathrm{R}_{\mathrm{ON}, \mathrm{sp}}$ of $0.136 \mathrm{~m} \Omega-\mathrm{cm}^{2}$ and $\mathrm{V}_{\mathrm{BR}}$ of $403 \mathrm{~V}$ achieved a record power figure of merit ( $\mathrm{PFOM}=\mathrm{V}_{\mathrm{BR}^{2}} / \mathrm{R}_{\mathrm{ON}, \mathrm{sp}}$ ) of $1194 \mathrm{M} \Omega / \mathrm{cm}^{2}$. This record value of PFoM supports the viability of $\mathrm{AlN} / \beta-\mathrm{Ga}_{2} \mathrm{O}_{3}$ HEMT for high voltage Nanoelectronics applications.

\section{RF CHARACTERISTICS}

The high-frequency RF performance of field-plate T-gate $\mathrm{AlN} / \beta-\mathrm{Ga}_{2} \mathrm{O}_{3}$ HEMT is investigated to estimate current gain cutoff frequency $\left(\mathrm{f}_{\mathrm{T}}\right)$ and maximum oscillation frequency ( $\left.f_{\text {MAX }}\right)$. This part of the simulation is performed using a small signal analysis with ac frequency varying from $1 \mathrm{GHz}$ to 200 $\mathrm{GHz}$ at $\mathrm{V}_{\mathrm{GS}}=-1 \mathrm{~V}$ and $\mathrm{V}_{\mathrm{DS}}=12 \mathrm{~V}$ corresponding to $\mathrm{g}_{\mathrm{m}}$ peak. Post simulation results show $\mathrm{f}_{\mathrm{T}}$ of $68 \mathrm{GHz}$ and $\mathrm{f}_{\mathrm{MAX}}$ of 142 $\mathrm{GHz}$ and shown in Fig. 8. However, the estimated value of $\mathrm{f}_{\mathrm{T}}$ is significantly lower than the previously reported $\mathrm{f}_{\mathrm{T}}$ value by our group for $\mathrm{AlN} / \beta-\mathrm{Ga}_{2} \mathrm{O}_{3} \mathrm{HEMT}$ with gate-length $\mathrm{L}_{\mathrm{G}}$ of 50 $\mathrm{nm}$. Here, the lower $\mathrm{f}_{\mathrm{T}}$ value can be explained based on the relatively large gate capacitance of T-gate as $f_{T} \propto 1 / C_{G G}$, where $\mathrm{C}_{\mathrm{GG}}$ is the gate capacitance, and also reported in [21].

\section{BENCHMARKING}

DC and RF parameters for the simulated $\mathrm{AlN} / \beta-\mathrm{Ga}_{2} \mathrm{O}_{3}$ HEMT, along with similar devices reported recently, are provided in Table 1 . The improved parameters are mainly due to the one-order higher 2DEG density $\left(\mathrm{n}_{\mathrm{s}}\right)$ as compared to $\mathrm{n}_{\mathrm{s}} \approx$ $10^{12} \mathrm{~cm}^{-2}$ for delta-doped $\beta-\mathrm{Ga}_{2} \mathrm{O}_{3}$ MESFET [22]. In addition, a higher conduction band offset at the heterointerface ensures highly confined charge carriers in the quantum triangular well. Finally, the device is benchmarked in the $\mathrm{R}_{\mathrm{ON}, \mathrm{sp}}$ versus $\mathrm{V}_{\mathrm{BR}}$ plot along with other suitable reported devices, the respective plot is shown by Fig. 9.

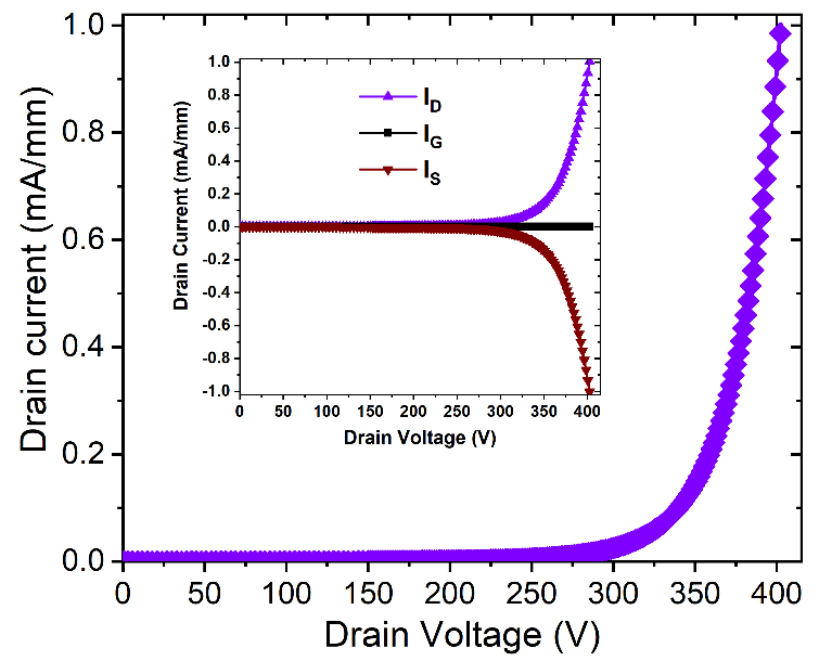

Fig. 6. Off-state breakdown characteristics of the AlN $/ \beta-\mathrm{Ga}_{2} \mathrm{O}_{3} \mathrm{HEMT}$ using field-plate T-gate with head length $=0.18 \mu \mathrm{m}$ and foot length $=0.12 \mu \mathrm{m}(=$ $\mathrm{L}_{\mathrm{G}}$ ). Inset: Three terminal breakdown characteristics. $\mathrm{A} \mathrm{V}_{\mathrm{BR}}$ of $403 \mathrm{~V}$ is estimated corresponding to $\mathrm{I}_{\mathrm{DS}}=1 \mathrm{~mA} / \mathrm{mm}$.

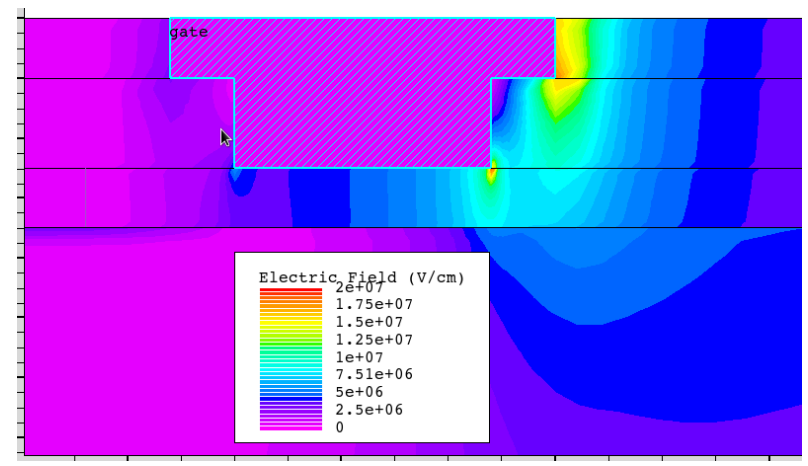

Fig. 7. Electric field profile (log scale) inside the simulated device structure at $I_{D S}=1 \mathrm{~mA} / \mathrm{mm}$, electric field peaks appear around drain side edges of field-plate T-gate. 


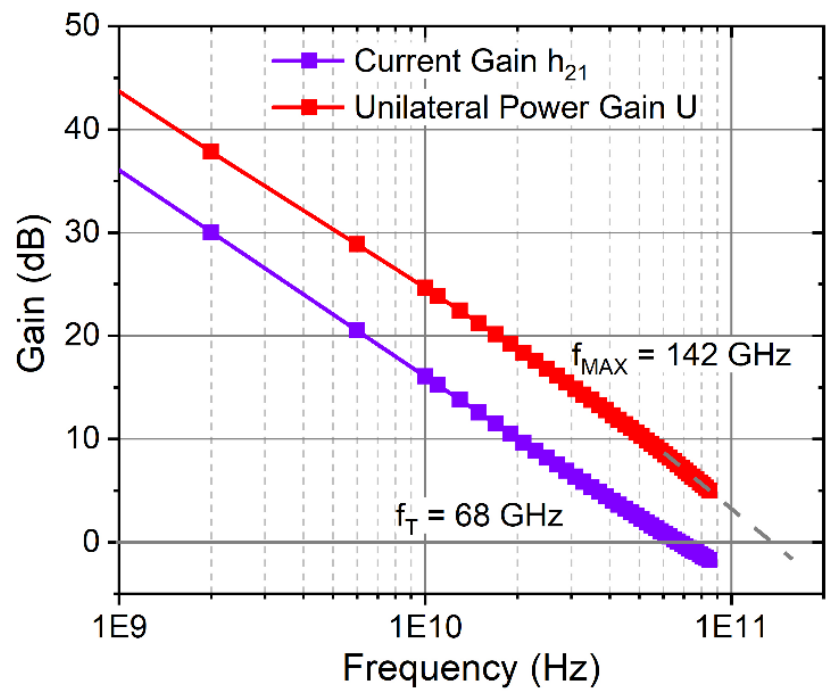

Fig. 8. Small-signal RF performance of $\mathrm{AlN} / \beta-\mathrm{Ga}_{2} \mathrm{O}_{3} \mathrm{HEMT}$ with field plate $\mathrm{T}$-gate, DC operating point $\mathrm{V}_{\mathrm{DS}}=12 \mathrm{~V}, \mathrm{~V}_{\mathrm{GS}}=-1 \mathrm{~V}$ is applied.

Table 1. DC and RF parameters of field plate T-gate AIN $/ \beta-\mathrm{Ga}_{2} \mathrm{O}_{3} \mathrm{HEMT}$ and of T-gate $\beta-\mathrm{Ga}_{2} \mathrm{O}_{3}$ MESFET [22].

\begin{tabular}{lcc}
\hline \hline & Proposed device & Ref [22] \\
\hline \hline $\mathrm{n}_{\mathrm{s}}\left(\mathrm{cm}^{-2}\right)$ & $10^{13}$ & $10^{12}$ \\
$\mathrm{~V}_{\mathrm{TH}}(\mathrm{V})$ & -3.8 & -6 \\
$\mathrm{I}_{\mathrm{ON}} / \mathrm{I}_{\mathrm{OFF}}$ & $10^{7}$ & $10^{8}$ \\
$\mathrm{I}_{\mathrm{D}, \mathrm{MAX}}(\mathrm{A} / \mathrm{mm})$ & 1.32 & 0.26 \\
$\mathrm{~g}_{\mathrm{MAX}}(\mathrm{S} / \mathrm{mm})$ & 0.32 & 0.044 \\
$\mathrm{R}_{\mathrm{ON}}(\Omega-\mathrm{mm})$ & 7.2 & - \\
$\mathrm{R}_{\mathrm{ON}, \text { sp }}\left(\mathrm{m} \Omega-\mathrm{cm}^{-2}\right)$ & 0.136 & - \\
$\mathrm{f}_{\mathrm{T}} / \mathrm{f}_{\mathrm{MAX}}(\mathrm{GHz})$ & $68 / 142$ & $27 / 16$
\end{tabular}

\section{CONCLUSION}

In summary, DC and RF characteristics of $\mathrm{AlN} / \beta-\mathrm{Ga}_{2} \mathrm{O}_{3}$ HEMT with field-plate $\mathrm{T}$-gate are investigated via 2-D simulations. A high 2DEG density in the order of $10^{13} \mathrm{~cm}^{-2}$ is estimated at the heterointerface of $\mathrm{AlN} / \beta-\mathrm{Ga}_{2} \mathrm{O}_{3}$ HEMT, mainly because of the highly polarized thin AlN barrier layer. Consequently, a maximum current density of $1.23 \mathrm{~A} / \mathrm{mm}$ and peak transconductance of $0.32 \mathrm{~S} / \mathrm{mm}$ are obtained. The proposed device employed a field plate $\mathrm{T}$ gate with headlength $\mathrm{L}_{\mathrm{HL}}$ of $180 \mathrm{~nm}$ and foot-length $\mathrm{L}_{\mathrm{FL}}$ of $120 \mathrm{~nm}$ to optimize its DC as well as RF performance. The T-gate effectively controls the channel and a threshold voltage of $3.8 \mathrm{~V}$ is estimated. The device has an ON-resistance of 7.2 $\Omega-\mathrm{mm}$, and a specific on-resistance of $0.136 \mathrm{~m} \Omega-\mathrm{cm}^{2}$ corresponding to $\mathrm{L}_{\mathrm{SD}}$ of $1.4 \mu \mathrm{m}$ for the proposed device. Furthermore, using the impact ionization model and threeterminal breakdown characteristics, a breakdown voltage of $403 \mathrm{~V}$ is estimated, and combining $\mathrm{R}_{\mathrm{ON}, \mathrm{sp}}$, and $\mathrm{V}_{\mathrm{BR}}$, a record PFoM of 1194 is estimated. The proposed device structure investigated here demonstrates the potential of $\mathrm{AlN} / \mathrm{\beta}-\mathrm{Ga}_{2} \mathrm{O}_{3}$ HEMTs for futuristic high-power Nanoelectronics applications.

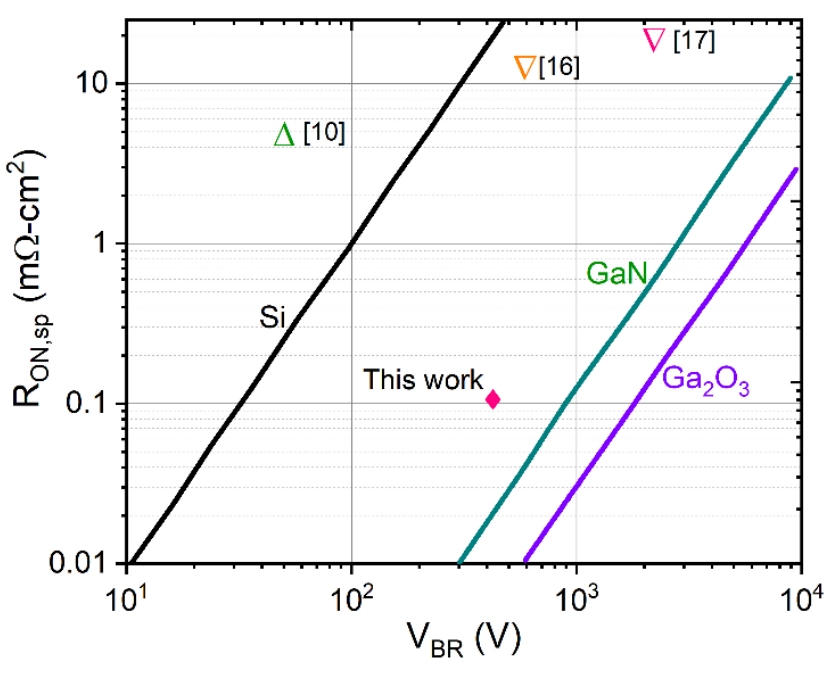

Fig. 9. $\mathrm{R}_{\mathrm{ON}, \mathrm{sp}}$ versus $\mathrm{V}_{\mathrm{BR}}$ for the field plate $\mathrm{T}$ gate $\mathrm{AlN} / \mathrm{\beta Ga}_{2} \mathrm{O}_{3} \mathrm{HEMT}$ along with some other $\beta-\mathrm{Ga}_{2} \mathrm{O}_{3}$ devices. Data are shown relative to theoretical limits for $\mathrm{Si}, \mathrm{GaN}$ and $\mathrm{Ga}_{2} \mathrm{O}_{3}$ materials.

\section{ACKNOWLEDGEMENT}

Visvesvaraya Young Faculty Research Fellowship by Ministry of Electronics and Information Technology (MeitY), Govt. of India being implemented by Digital India Corporation.

\section{REFERENCES}

[1] S. J. Pearton, F. Ren, M. Tadjer, and J. Kim, "Perspective: $\mathrm{Ga}_{2} \mathrm{O}_{3}$ for ultra-high power rectifiers and MOSFETS," J. Appl. Phys., vol. 124, no. 22, 2018, doi: 10.1063/1.5062841.

[2] S. J. Pearton et al., "A review of $\mathrm{Ga}_{2} \mathrm{O}_{3}$ materials, processing, and devices,” Appl. Phys. Rev., vol. 5, no. 1, p. 011301, Mar. 2018, doi: 10.1063/1.5006941.

[3] E. Ahmadi and Y. Oshima, "Materials issues and devices of $\alpha$ - And $\beta$ $\mathrm{Ga}_{2} \mathrm{O}_{3}$," Journal of Applied Physics, vol. 126, no. 16. 2019, doi: 10.1063/1.5123213.

[4] R. Singh et al., "The dawn of $\mathrm{Ga}_{2} \mathrm{O}_{3}$ HEMTs for high power electronics - A review," Mater. Sci. Semicond. Process., vol. 119, no. September 2019, p. 105216, Nov. 2020, doi: 10.1016/j.mssp.2020.105216.

[5] Z. Hu et al., "Field-Plated Lateral $\beta-\mathrm{Ga}_{2} \mathrm{O}_{3}$ Schottky Barrier Diode with High Reverse Blocking Voltage of More Than $3 \mathrm{kV}$ and High DC Power Figure-of-Merit of $500 \mathrm{MW} / \mathrm{cm}^{2}$," IEEE Electron Device Lett., pp. 1-1, 2018, doi: 10.1109/LED.2018.2868444.

[6] J. Yang, F. Ren, M. Tadjer, S. J. Pearton, and A. Kuramata, " $\mathrm{Ga}_{2} \mathrm{O}_{3}$ Schottky rectifiers with 1 ampere forward current, $650 \mathrm{v}$ reverse breakdown and 26.5 MW.cm-2 figure-of-merit," AIP Adv., vol. 8, no. 5, 2018, doi: 10.1063/1.5034444.

[7] M. Higashiwaki, K. Sasaki, A. Kuramata, T. Masui, and S. Yamakoshi, "Gallium oxide $\left(\mathrm{Ga}_{2} \mathrm{O}_{3}\right)$ metal-semiconductor field-effect transistors on single-crystal $\beta-\mathrm{Ga}_{2} \mathrm{O}_{3}(010)$ substrates," Appl. Phys. Lett., vol. 100, no. 1, pp. 3-6, 2012, doi: 10.1063/1.3674287.

[8] S. Krishnamoorthy, Z. Xia, S. Bajaj, M. Brenner, and S. Rajan, "Deltadoped $\beta$-gallium oxide field-effect transistor," Appl. Phys. Express, vol. 10, no. 5, p. 051102, May 2017, doi: 10.7567/APEX.10.051102.

[9] M. Higashiwaki et al., "Depletion-mode $\mathrm{Ga}_{2} \mathrm{O}_{3}$ metal-oxidesemiconductor field-effect transistors on $\beta-\mathrm{Ga}_{2} \mathrm{O}_{3}(010)$ substrates and temperature dependence of their device characteristics," Appl. Phys. Lett., vol. 103, no. 12, pp. 1-5, 2013, doi: 10.1063/1.4821858.

[10] A. J. Green et al., "3.8-MV/cm Breakdown Strength of MOVPEGrown Sn-Doped $\beta-\mathrm{Ga}_{2} \mathrm{O}_{3}$ MOSFETs," IEEE Electron Device Lett., vol. 37, no. 7, pp. 902-905, 2016, doi: 10.1109/LED.2016.2568139.

[11] N. Moser et al., "Ge-Doped $\beta-\mathrm{Ga}_{2} \mathrm{O}_{3}$ MOSFETs," IEEE Electron Device Lett., vol. 38, no. 6, pp. 775-778, Jun. 2017, doi: 10.1109/LED.2017.2697359.

[12] N. A. Moser et al., "High pulsed current density $\beta-\mathrm{Ga}_{2} \mathrm{O}_{3}$ MOSFETs verified by an analytical model corrected for interface charge," Appl. Phys. Lett., vol. 110, no. 14, p. 143505, Apr. 2017, doi: 10.1063/1.4979789.

[13] K. D. Chabak et al., "Enhancement-mode $\mathrm{Ga}_{2} \mathrm{O}_{3}$ wrap-gate fin fieldeffect transistors on native (100) $\beta$-Ga 2 O 3 substrate with high 
breakdown voltage,” Appl. Phys. Lett., vol. 109, no. 21, p. 213501, Nov. 2016, doi: 10.1063/1.4967931.

[14] M. H. Wong, Y. Nakata, A. Kuramata, S. Yamakoshi, and M. Higashiwaki, "Enhancement-mode $\mathrm{Ga}_{2} \mathrm{O}_{3}$ MOSFETs with Si-ionimplanted source and drain,” Appl. Phys. Express, vol. 10, no. 4, p. 041101, Apr. 2017, doi: 10.7567/APEX.10.041101.

[15] T. Sato, K. Uryu, J. Okayasu, M. Kimishima, and T. K. Suzuki, "Suppression of drain-induced barrier lowering by double-recess overlapped gate structure in normally-off AlGaN-GaN MOSFETs," Appl. Phys. Lett., vol. 113, no. 6, pp. 2-6, 2018, doi 10.1063/1.5039886.

[16] K. D. Chabak et al., "Recessed-Gate Enhancement-Mode $\beta-\mathrm{Ga}_{2} \mathrm{O}_{3}$ MOSFETs," IEEE Electron Device Lett., vol. 39, no. 1, pp. 67-70, Jan. 2018, doi: 10.1109/LED.2017.2779867.

[17] Z. Feng et al., "Design and fabrication of field-plated normally off $\beta$ $\mathrm{Ga}_{2} \mathrm{O}_{3}$ MOSFET with laminated-ferroelectric charge storage gate for high power application,” Appl. Phys. Lett., vol. 116, no. 24, p. 243503, Jun. 2020, doi: 10.1063/5.0010561.

[18] J. Wang et al., " $\varepsilon-\mathrm{Ga}_{2} \mathrm{O}_{3}$ : A Promising Candidate for High-ElectronMobility Transistors," IEEE Electron Device Lett., vol. 41, no. 7, pp. 1052-1055, 2020, doi: 10.1109/LED.2020.2995446.

[19] R. Singh, T. R. Lenka, R. T. Velpula, B. Jain, H. Q. T. Bui, and H. P. T. Nguyen, "A novel $\beta-\mathrm{Ga}_{2} \mathrm{O}_{3}$ HEMT with fT of $166 \mathrm{GHz}$ and X-band POUT of $2.91 \mathrm{~W} / \mathrm{mm}$," Int. J. Numer. Model. Electron. Networks, Devices Fields, vol. 34, no. 1, pp. 1-11, 2021, doi: 10.1002/jnm.2794.

[20] X. Yan, I. S. Esqueda, J. Ma, J. Tice, and H. Wang, "High breakdown electric field in $\beta-\mathrm{Ga}_{2} \mathrm{O}_{3}$ /graphene vertical barristor heterostructure,'
Appl. Phys. Lett., vol. 112, no. 3, pp. 1-5, 2018, doi: 10.1063/1.5002138

[21] J. Mateos, T. González, D. Pardo, V. Hoel, and A. Cappy, "Effect of the T-gate on the performance of recessed HEMTs. A Monte Carlo analysis," Semicond. Sci. Technol., vol. 14, no. 9, pp. 864-870, 1999, doi: 10.1088/0268-1242/14/9/320.

[22] Z. Xia et al., " $\beta-\mathrm{Ga}_{2} \mathrm{O}_{3}$ Delta-Doped Field-Effect Transistors With Current Gain Cutoff Frequency of $27 \mathrm{GHz}$," IEEE Electron Device Lett., vol. 40, no. 7, pp. 1052-1055, Jul. 2019, doi: 10.1109/LED.2019.2920366.

[23] D. S. Software, “ATLAS User's Manual,” vol. II, no. November, pp. 567-1000, 2018.

[24] S. Poncé and F. Giustino, "Structural, electronic, elastic, power, and transport properties of $\beta-\mathrm{Ga}_{2} \mathrm{O}_{3}$ from first principles," Physical Review Research, vol. 2, no. 3. p. 033102, 2020, [Online]. Available: https://link.aps.org/doi/10.1103/PhysRevResearch.2.033102.

[25] K. Ghosh and U. Singisetti, "Impact ionization in $\beta-\mathrm{Ga}_{2} \mathrm{O}_{3}$," J. Appl. Phys., vol. 124, no. 8, p. 085707, Aug. 2018, doi: 10.1063/1.5034120.

[26] K. Ghosh and U. Singisetti, "Ab initio velocity-field curves in monoclinic $\beta-\mathrm{Ga}_{2} \mathrm{O}_{3}$," J. Appl. Phys., vol. 122, no. 3, p. 035702, Jul. 2017, doi: 10.1063/1.4986174.

[27] H. Lu, S. Member, B. Hou, L. Yang, X. Niu, and Z. Si, “AlN / GaN / InGaN Coupling-Channel HEMTs for Improved $\mathrm{g} \mathrm{m}$ and Gain Linearity," pp. 1-6, 2021. 